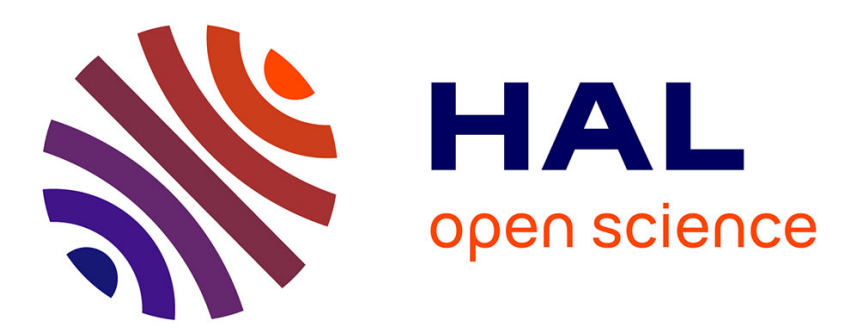

\title{
Evaluation of the structure (or nonlinearity) parameter by peak-shift method from volumetric heating data of PET
}

Petr Slobodian, Martin Zatloukal, Petr Sáha

\section{- To cite this version:}

Petr Slobodian, Martin Zatloukal, Petr Sáha. Evaluation of the structure (or nonlinearity) parameter by peak-shift method from volumetric heating data of PET. Journal of Physics and Chemistry of Solids, 2009, 69 (4), pp.975. 10.1016/j.jpcs.2007.11.008 . hal-00526541

HAL Id: hal-00526541

https://hal.science/hal-00526541

Submitted on 15 Oct 2010

HAL is a multi-disciplinary open access archive for the deposit and dissemination of scientific research documents, whether they are published or not. The documents may come from teaching and research institutions in France or abroad, or from public or private research centers.
L'archive ouverte pluridisciplinaire HAL, est destinée au dépôt et à la diffusion de documents scientifiques de niveau recherche, publiés ou non, émanant des établissements d'enseignement et de recherche français ou étrangers, des laboratoires publics ou privés. 


\section{Author's Accepted Manuscript}

Evaluation of the structure (or nonlinearity) parameter $x$ by peak-shift method from volumetric heating data of PET

Petr Slobodian, Martin Zatloukal, Petr Sáha

PII: $\quad$ S0022-3697(07)00735-4

DOI: $\quad$ doi:10.1016/j.jpcs.2007.11.008

Reference: $\quad$ PCS 5316

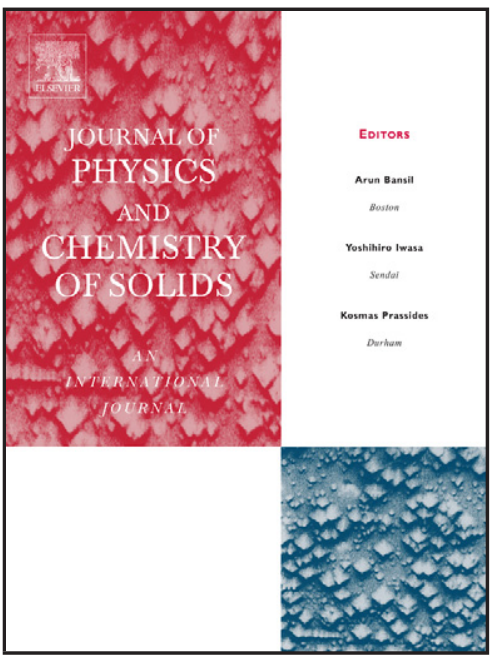

www.elsevier.com/locate/jpcs

To appear in: Journal of Physics and Chemistry of Solids

Received date: $\quad 15$ May 2007

Revised date: $\quad 15$ August 2007

Accepted date: 14 November 2007

Cite this article as: Petr Slobodian, Martin Zatloukal and Petr Sáha, Evaluation of the structure (or nonlinearity) parameter $x$ by peak-shift method from volumetric heating data of PET, Journal of Physics and Chemistry of Solids (2007), doi:10.1016/j.jpcs.2007.11.008

This is a PDF file of an unedited manuscript that has been accepted for publication. As a service to our customers we are providing this early version of the manuscript. The manuscript will undergo copyediting, typesetting, and review of the resulting galley proof before it is published in its final citable form. Please note that during the production process errors may be discovered which could affect the content, and all legal disclaimers that apply to the journal pertain. 


\section{Evaluation of the structure (or Nonlinearity) parameter $x$ by peak-shift method from volumetric heating data of PET}

Petr Slobodian* Martin Zatloukal and Petr Sáha

Tomas Bata University in Zlín, Faculty of Technology, T.G.M. 275, 76272 Zlín, Czech Republic

*Tel. +420 57603 1350, Fax. +420 57603 1444, e-mail: Slobodian@ft.utb.cz

\section{ABSTRACT}

The structure parameter $x$, defining the temperature and structure relative contribution to the relaxation times, was evaluated applying the peak-shift method (PSM) onto volumetric heating data of poly(ethylene terephthalate) (PET) with content of crystallinity 2.6 wt. \%. The method of Mercury-in-Glass Dilatometry (MIG) and three-step thermal cycle procedure were used. Two sets of heating scans were measured as a function of the amount of volume isothermal relaxation for two different relaxation temperatures below $T_{g}\left(60^{\circ} \mathrm{C}\right.$ and $\left.52^{\circ} \mathrm{C}\right)$, whereas other experimental variables were kept constant. The experimentally determined heating isobar inflection temperature is a linear function of the amount of volume relaxation, which satisfy the application of PSM method for structure parameter $\mathrm{x}$ determination from volumetric heating data. The value of structure parameter of the used PET is independent of relaxation temperature and equal to $0.50 \pm 0.02$. Finally, the shift of heating isobar inflection temperature with relaxation temperature $\left(60^{\circ} \mathrm{C}, 56^{\circ} \mathrm{C}, 52^{\circ} \mathrm{C}\right.$ and $\left.48^{\circ} \mathrm{C}\right)$ measured for constant amount of volume isothermal relaxation was found to be linear, with the slope of 0.13 .

Key words: peak-shift method, structure parameter, thermal expansion coefficient, volume relaxation, PET, glass transition temperature

\section{INTRODUCTION}

The fundamental features of amorphous solid materials, such as glass transition transformation and consecutive structural relaxation phenomenon or the behavior of relaxed structures during their isobaric heating, can be better understood and approached through the analysis of glass-formation kinetics. One of the most powerful approaches is the concept of the fictive temperature, $T_{f}$, which is used to characterize the structural state of the glass. The concept is satisfactorily expressed in an empirical relationship called Tool-NarayanaswamyMoynihan (TNM) equation [1,2]:

$\ln \tau_{i}=\ln A+\frac{x \Delta h^{*}}{R T}+\frac{(1-x) \Delta h^{*}}{R T_{f}}$

where $\tau_{i}$ is the $i^{\text {th }}$ relaxation time in the distribution of relaxation times, $A$ means the pre-exponential factor reaching the value of $\tau_{i}$ at equilibrium and infinitely high temperature, $\Delta h^{*}$ represents the apparent activation energy for structural relaxation, $R$ is the gas constant, and $x(0 \leq x \leq 1)$ stands for a non-linearity or structure parameter defining the relative contributions of temperature and structure to the relaxation times. 
With the help of well designed calorimetric or volumetric experiments it is possible to determine particular parameters of TNM equation. Hutchinson et al developed so-called peak-shift method (PSM), which is capable, among others, to evaluate structure parameter $x$ from calorimetric measurements [3-7]. The applicability and validity is also supported by theoretical Hutchinson's and Kovacs's work [8], where sensitiveness of parameter $x$ to volumetric peaks is clearly demonstrated. This method is based on quantification of the peak temperature, $T_{p}$, shift at $c_{p}(T)$ or $\alpha(T)$ dependences caused by variation of experimental variables. The relationship between $T_{p}$ and one of the variables (while the others are held constant) is usually found to be linear. The shift factor used for the determination of parameter $x$ is calculated by linear extrapolation of the data obtained from experiments based on three-step cycles. This procedure is schematically illustrated in Fig. 1. It involves cooling of the sample at constant cooling rate, $q_{1}$, to aging or relaxation temperature $T_{a}<T_{g}$ from annealing temperature $T_{i}>T_{g}$, where the sample was left to anneal in order to erase any previous thermal or mechanical history. It is followed by isothermal relaxation for aging time $t_{a}$. Finally, the sample is reheated at a constant heating rate, $q_{2}$, to a temperature well above $T_{g}$.

This method can be also understood from the schematic illustration in Fig. 2. [9]. In the figure, part A clearly demonstrates an abrupt change in volume, $V$, which is usually measured during isobaric heating of slowly-cooled and/or annealed specimens through the glass transition region. (The same also applies to enthalpy.) This almost discontinuous increase in $V$ with an inflection point is followed by steady state regime at sufficiently high temperature. The derivation of $V(T)$ records produces rather sharp peaks in the thermal expansion coefficient, $\alpha$, which is illustrated in part B and was theoretically or experimentally shown in [8] and [9-11], or even more commonly in the specific heat capacity, $c_{p}$, [3-7] in the case of $H(T)$ dependences. The curve passes thought a maximum at the mentioned peak temperature, $T_{p}$, and then decreases reaching the values characteristic of the liquid state. In Fig. 2 subscripts $t_{0}, t_{a}$ and $\infty$ define the initial volume after achieving relaxation temperature, the volume after isothermal relaxation for relaxation time $t_{a}$, and finally $\infty$ means equilibrium volume at $T_{a}$. Thermal expansion coefficient is mentioned as a characteristic value of glassy state, $g$, or liquid, $l$. On temperature coordinate, $T_{g}\left(q_{l}\right)$ represents conventionally determined glass transition temperature from cooling scans, $T_{p}$ represents peak temperature corresponding with inflection point on $V(T)$ dependences, and $T_{i}$ is initial annealing temperature before cooling.

An important role in the process is played by the used method. The signal measured on conventional calorimeters represents directly the quantity, e.g. heat flow, which can be easily re-calculated after appropriate calibration to $c_{p}$. Thus most calorimetric experimental data is more suitable for conversion of $c_{p}(T)$ into $H(T)$ rather than the opposite way. On the other hand, the volumetric measurements represent usually directly measured $V(T)$ data which can be converted into $\alpha(T)$.

As mentioned above, the character of the peak described by its shape, size and its temperature position is a function of experimental variables. They can be defined as $q_{1}, \bar{\delta}_{V}$ or $\bar{\delta}_{H}, q_{2}$ and $T_{a}$. Here $q_{1}$ and $q_{2}$ mean cooling and heating rates, respectively, and quantities $\delta_{V}$ or $\delta_{H}$ represent the amount of volume or enthalpy isothermal relaxation at $T_{a}$. It must be kept in mind that the influence of thermal history is complex and it is necessary to separate individual effects $\left(q_{1}, \bar{\delta}_{H}, \bar{\delta}_{V}, q_{2}, T_{a}\right)$ on $T_{p}$, so each of the effects should be treated individually. 
The expansion of the peak area and peak shift to a higher temperature region is usually observed as the effect of extension of aging time, $t_{a}$ [3,5-19]. Here, a linear relationship between $T_{p}$ and $\bar{\delta}_{H}$ can be found. Hutchinson et al [3-9] define the normalized (dimensionless) shift by $\bar{\delta}_{H}$ as:

$\hat{s}\left(\bar{D}_{H}\right)=\Delta c_{p}\left(\frac{\partial T_{p}}{\partial \bar{\delta}_{H}}\right)_{q_{1}, T_{a}, q_{2}}$

where $\Delta c_{p}=c_{p, l}+c_{p, g}$ in $\left[\mathrm{J} \cdot \mathrm{g}^{-1} \cdot{ }^{\circ} \mathrm{C}^{-1}\right] ; c_{p, l}$ and $c_{p, g}$ represent specific heat capacities of the liquid and glass, respectively.

It has been shown [3-7] that this shift is interrelated and depends sensitively upon $x$ thought function $F(x)$ :

$F(x)=s\left(D_{H}\right)$

Theoreticaly it has been found $[3,4]$ that function $F(x)$ takes a simple hyperbolic form, Eq. (4), finally leading to the structure parameter $x$.

$\mathrm{F}(\mathrm{x})=\mathrm{x}^{-1}-1$

The reliability of this "enthalpic" approach was tested for a number of glassy polymers like PS [3], PC [6], PVAc [7], PMMA and its amorphous blends with PEO [13], poly[methyl( $\alpha$-n-alkyl)acrylates] [12], for partially [14] or fully [15-17] cured epoxy resin with different curing agents, or for organic glass forming substances like glucose, fructose and their mixtures [18] or for inorganic glasses based on composition like $\mathrm{AgI}-\mathrm{AgPO}_{3}-\mathrm{Ag}_{2} \mathrm{Mo}_{4}$ [5] or recently for amorphous selenium [19].

Although this method was originally developed for both enthalpy and volumetric measurements, it has been entirely applied only onto the former, therefore dilatometric experimental data is missing in literature. The same is true for the key parameter of structural relaxation, $x$, for PET - it is not accessible.

Thus the main aim of this paper is to use volumetric heating data to determine the structure parameter $x$ by the peak shift-method adapted for PET material.

\section{EXPERIMENTAL}

Tested material: Poly(ethylene terephthalate), PET, was purchased from Aldrich Chemical Company. From the original granules a specimen for dilatometric measurements was prepared by pouring the melted polymer $\left(290^{\circ} \mathrm{C}\right)$ into room-temperature water. The density of the prepared quenched PET sample inserted into the dilatometer was measured to be $\rho=1.3391 \mathrm{~g} . \mathrm{cm}^{-3}$. Comparing this value to the density of purely amorphous PET, $\rho_{a}=1.335 \mathrm{~g} . \mathrm{cm}^{-3}[16]$ and to the calculated density of crystalline phase, $\rho_{c}=1.515 \mathrm{~g} \cdot \mathrm{cm}^{-3}[17]$, the degree of crystallinity can be expressed as the weight fraction, $w$ :

$w=\frac{\rho_{c}}{\rho} \frac{\left(\rho-\rho_{a}\right)}{\left(\rho_{c}-\rho_{a}\right)}$

The calculated value was $w=2.6$ wt. \%. Moreover, independent determination of sample crystallinity was carried out using a wide-angle X-ray diffraction (HZG 4 Diffractometer) giving the degree of crystallinity $2.1 \%$ [10].

Method: A Mercury-in-Glass Dilatometer (MIG) constructed according to ASTM Standard D 864-52 [15] was used for experimental measurements, with Kovacs's [21] remarks on the filling procedure. The concrete experimental procedure was adapted according to [24]. The dilatometer capillary was calibrated by injecting a 
known amount of liquid and measuring the length of the column of liquid. Its diameter was calculated to be $0.79 \pm 0.01 \mathrm{~mm}$. Before sealing, the dilatometer was washed with a solution of potassium dichromate in sulfuric acid and then washed with distilled water and ethanol. The dilatometer with a specimen was filled with pure mercury (99.999\%) under vacuum of about $2 \mathrm{~Pa}$ after its evacuation for 4 hours holding the dilatometer "bulb" with specimen at $\sim 65^{\circ} \mathrm{C}$. The mercury was filtered thought filter $\mathrm{G} 2$ before its use to remove mercury oxidizes. The amount of placed PET was approx. $1.71 \mathrm{~cm}^{3}$ and $7.41 \mathrm{~cm}^{3}$ of mercury. The filled dilatometer did not show any travel of mercury meniscus, at most several millimeters, after turning it upside down, i.e it was filled correctly.

All temperature programs of the dilatometer were realized by immersing the dilatometer into a precision thermostatic bath (JULABO HP-4) filled with silicon oil. The accuracy of volume changes measurements by this method was about $\sim 1 \times 10^{-5} \mathrm{~cm}^{3} . \mathrm{cm}^{-3}$ in respect to the amount of PET, mercury, dilatometer capillary bore and temperature fluctuations of thermostatic bath. The temperature lag between the temperature of silicon oil and the temperature inside the dilatometer was measured. It was determined with a K-type thermocouple placed inside the sample inserted into an additional dilatometer having the same geometry, amount of sample and mercury. For the used cooling/heating rates $\left(60^{\circ} \mathrm{C} . \mathrm{h}^{-1}\right)$ the lag was determined to be $0.7^{\circ} \mathrm{C}$. All experimental data were corrected by this value.

Three-step thermal cycles: The above described three-step thermal cycle method, Fig. 1, was used to perform volumetric heating scans. The effect of volume isothermal relaxation, $\bar{\delta}_{V}$, was studied while the other variables were held constant. Also the effect of relaxation temperature for constant $\bar{\delta}_{V}$ was proved. The used experimental settings are listed in Table 1.

Isothermal relaxation: Isothermal volume relaxation data was collected at aging temperatures $T_{a}=60^{\circ} \mathrm{C}$ and $52^{\circ} \mathrm{C} . T_{a}$ was achieved by cooling from equilibrium above $T_{g}$ at the cooling rate of $60^{\circ} \mathrm{C} \cdot \mathrm{h}^{-1}$. The initial time, $t_{0}$, for collecting experimental data was the moment when $T_{a}$ was reached.

\section{RESULTS AND DISCUSION}

Volumetric glass transition temperature, $T_{g}$, is usually assessed from the volume-temperature dependence measured during sample cooling at a constant cooling rate from the equilibrium liquid state to the glassy state, and is defined as the intersection of the equilibrium liquid line with the asymptotic glassy line. Using this method, $T_{g}$ of the tested PET was determined to be $68.5^{\circ} \mathrm{C}$ at cooling rate $q_{1}=60^{\circ} \mathrm{C} \cdot \mathrm{h}^{-1}$, as can be seen in Fig. 3 (the liquid and glassy lines are dashed). Thermal expansion coefficients were calculated as volume normalized slopes, Eq. (6), of both linear parts - above (liquid line), $\alpha_{l}=5.6 \times 10^{-4}{ }^{\circ} \mathrm{C}^{-1}$, and below (glassy line), $\alpha_{g}=2.3 \times 10^{-4}{ }^{\circ} \mathrm{C}^{-1}$, glass transition temperature, leading to $\Delta \alpha=\alpha_{l}-\alpha_{g}=3.3 \times 10^{-4}{ }^{\circ} \mathrm{C}^{-1}$.

$\alpha=\frac{1}{v} \frac{d v}{d T}$

Fig. 3 also includes the heating curve for the same rate $q_{2}=q_{1}=60^{\circ} \mathrm{C} \cdot \mathrm{h}^{-1}$ after annealing at $56^{\circ} \mathrm{C}$ for 422 hours, the shape of which significantly differs from the cooling curve. A typical abrupt change can be seen on volume-temperature scan in the glass transition region. From heating scans the value of $T_{g}$ can be determined as a characteristic point at the abrupt part of the heating isobar. In the present work, the inflection point, $T_{i p}$, was chosen for this purpose, which corresponds with the peak temperature, $T_{i p}=T_{p}$, on the relevant derived heating 
isobaric curve. It was found that $T_{i p}=77.3^{\circ} \mathrm{C}$ from the heating mode is $8.8^{\circ} \mathrm{C}$ higher than $T_{g}$ determined from the cooling test.

The effect of relaxation/aging time, $t_{a}$, for two different relaxation temperatures $\left(60^{\circ} \mathrm{C}\right.$ and $\left.52^{\circ} \mathrm{C}\right)$ onto the shape and position of heating scans is presented in Fig. 4. It is nicely visible that an increase in the relaxation time leads to a decrease in specific volume with a consequent increase in the abrupt transition from the glassy to liquid line, which is followed by a shift to higher temperature. This temperature shift was consequently quantified by the slope of heating isobar inflection temperature, $T_{i p}$, vs. relaxation time in linear-log scale and was found to be $1.9^{\circ} \mathrm{C}$.

Isothermally measured volume relaxation curves vs. relaxation time in linear-log scale for two relaxation temperatures $\left(60^{\circ} \mathrm{C}\right.$ and $\left.52^{\circ} \mathrm{C}\right)$ and the longest experimental relaxation times $(270$ and 960 hours $)$ are presented in Fig. 5. The "Volume Relaxation" is defined here as

$v_{\left(t_{a}\right)}-v_{\left(t_{0}\right)}$

where $v_{\left(t_{0}\right)}$ and $v_{\left(t_{a}\right)}$ represent specific volumes (initial and relaxation time dependent, respectively) at isothermal conditions characterized by $T_{a}$. In this figure, an initial relaxation plateau is observed at low relaxation times whereas at higher times the curves linearly decrease. Within this high relaxation time range, the intensity of volume relaxation can be quantified through volume relaxation rate (Eq. 8), which was found to be equal to $5.9 \times 10^{-4} \mathrm{~cm}^{3} \cdot \mathrm{cm}^{-3}$ in this case.

$\widetilde{\beta}=\frac{1}{v} \frac{d v}{d \log t_{a}}$

It is not difficult to show (by combination of Eqs. 3, 4, 7 and Eqs. 6, 8, 9, as given in [3]) that Hutchinson volumetric peak shift can be expressed by the following equation:

$\hat{\mathrm{s}}\left(\overline{\mathrm{D}}_{\mathrm{V}}\right)=\Delta \overline{\bar{\alpha}}\left(\frac{\partial \mathrm{T}_{\mathrm{ip}}}{\partial \bar{\delta}_{\mathrm{V}}}\right)_{\mathrm{q}_{1}, \mathrm{~T}_{\mathrm{a}}, \mathrm{q}_{2}}=\mathrm{x}^{-1}-1$

where the "Amount of Volume Relaxation", $\bar{\delta}_{V}$, is defined as $\left|v_{\left(t_{a}\right)}-v_{\left(t_{0}\right)}\right|$, the $\Delta \bar{\alpha}$ variable can be expressed as $\Delta \bar{\alpha}=\bar{\alpha}_{l}-\bar{\alpha}_{g}$, where $\bar{\alpha}_{l}$ and $\bar{\alpha}_{g}$ represent slopes $(\mathrm{d} v / \mathrm{d} T)$ of the linear parts above and below $T_{g}$, respectively. In the case of the tested PET material the values were $\bar{\alpha}_{l}=4.2 \times 10^{-4} \mathrm{~cm}^{3} \cdot \mathrm{g}^{-1} \cdot{ }^{\circ} \mathrm{C}^{-1}$ and $\bar{\alpha}_{g}=1.7 \times 10^{-4} \mathrm{~cm}^{3} \cdot \mathrm{g}^{-1} \cdot{ }^{\circ} \mathrm{C}^{-1}$, leading to $\Delta \bar{\alpha}=2.5 \times 10^{-4} \mathrm{~cm}^{3} \cdot \mathrm{g}^{-1} \cdot{ }^{\circ} \mathrm{C}^{-1}$.

In order to determine the structure parameter $x$ from the volumetric data, it is necessary to find the slope $\Delta T_{i p} / \Delta \bar{\delta}_{V}$, i.e. the dependence of heating isobar inflection temperature vs. amount of volume relaxation (see Fig. 6). In the research we found slopes $4304{ }^{\circ} \mathrm{C} . \mathrm{g} . \mathrm{cm}^{-3}$ and $3876{ }^{\circ} \mathrm{C} . \mathrm{g} . \mathrm{cm}^{-3}$ for $60^{\circ} \mathrm{C}$ and $52^{\circ} \mathrm{C}$, respectively. Then, using Eq. (9), the structure parameter $x$ was determined for both considered temperatures as $x_{\left(60^{\circ} \mathrm{C}\right)}=0.48$ and $x_{\left(52^{\circ} \mathrm{C}\right)}=0.51$, i.e. equal to $x=0.50 \pm 0.02$. In this case, the value was supposed to be relaxation temperature independent, which is in good agreement with Hutchinson et al [3], who proved that the non-linearity parameter $x$ can be considered a material constant independent of all the experimental variables, such as relaxation temperature [3].

Hutchinson and co-workers in the same study [3] show that the shift of peak temperature, $T_{p}$, with relaxation temperature, $T_{a}$, for the same amount of enthalpy isothermal relaxation at different $T_{a}$ can be theoretically derived to provide a value close to zero, Eq. (10): 
$\left(\frac{\partial T_{p}}{\partial T_{a}}\right)_{q_{1}, \bar{\delta}_{H}, q_{2}} \approx 0$

However, the volumetric experimental data from the present study suggests that the heating isobar inflection temperatures, $T_{i p}$, for $T_{a}=60^{\circ} \mathrm{C}$ are shifted to higher values by $1.5-2.1^{\circ} \mathrm{C}$ for the same $\bar{\delta}_{V}$, leading to a slope of around 0.2 (from Eq. 10), as can be seen in Fig. 6. With the aim to quantify this effect much more precisely, volumetric experiments, keeping constant $\bar{\delta}_{V}$, were carried out for two additional relaxation temperatures $\left(56^{\circ} \mathrm{C}\right.$ and $\left.48^{\circ} \mathrm{C}\right)$ and summarized with previous experimental data in Fig. 7 . In more detail, heating isobar inflection temperatures, $T_{i p}$, were determined to be $73.6^{\circ} \mathrm{C}$ from the heating-curve after 144-hour aging at $48^{\circ} \mathrm{C}, 74.1^{\circ} \mathrm{C}$ after 79 hours at $52^{\circ} \mathrm{C}, 74.5^{\circ} \mathrm{C}$ after 54 hours at $56^{\circ} \mathrm{C}$ and $75.2^{\circ} \mathrm{C}$ after 43 hours at $60^{\circ} \mathrm{C}$. Using this data set, the slope given by Eq. 10 was found to be 0.13 for the tested PET. This is in good agreement with enthalpy-based experimental work of Hutchinson et al [3], who have revealed that for polystyrene the slope varies between $0.01-0.1$.

\section{CONCLUSION}

The research has proved that the peak-shift method can be applied to the volumetric data obtained from Mercury-in-Glass Dilatometry. The value of the structure parameter $x$ for PET material was found to be relaxation temperature independent and equal to $0.50 \pm 0.02$. Finally, it has been revealed that increasing relaxation temperature shifts the heating scans to a higher temperature, while other experimental conditions keep a constant amount of volume relaxation. 


\section{REFERENCES}

[1] J.M. Hutchinson, Physical aging of polymers, Prog. Polym. Sci. 20 (1995) 703-760.

[2] O.S. Narayanaswamy, A model of structural relaxation in glass, J. Am. Ceram. Soc. 54 (1971) 491-497.

[3] J.M. Hutchinson, M. Ruddy, Thermal cycling of glasses. 2. Experimental evaluation of the structure (or nonlinearity) parameter-x, J. Polym. Sci. Polym. Phys. 26 (1988) 2341-2366.

[4] J.M. Hutchinson, M. Ruddy, Structural recovery in glass - a critical evaluation of a paper by Avramov, Grantscharova and Gutzow, J. Non-Cryst. Solids 108 (1989) 225-232.

[5] J.M. Hutchinson, M.D. Ingram, A.J. Pappin, Structural recovery in silver-iodide containing glassesillustration of the use of the peak-shift method for the evaluation of the Narayanaswamy parameter-x, J. Non-Cryst. Solids 131-133 (1991) 483-487.

[6] J.M. Hutchinson, S. Smith, B. Horne, and G.M. Gourlay, Physical aging of polycarbonate: Enthalpy relaxation, creep response, and yielding behaviour, Macromolecules 32 (1999) 5046-5061.

[7] J.M. Hutchinson, P. Kumar, Enthalpy relaxation in polyvinyl acetate, Thermochim. Acta 391 (2002) 197-217.

[8] J.M. Hutchinson and A.J. Kovacs, Effects of thermal history on structural recovery of glasses during isobaric heating, Polym. Eng. Sci. 24 (1984) 1087-1103.

[9] J.M. Hutchinson and A.J. Kovacs, Simple phenomenological approach to thermal-behavior of glasses during uniform heating or cooling, Polym. Sci. Polym. Phys. 14 (1976) 1575-1590.

[10] J. Hadač, P. Slobodian, P. Sáha, Volume relaxation in amorphous and semicrystalline PET, J. Mater. Sci. 42 (2007) 3724-3731.

[11]P. Řiha, J. Hadač, P. Slobodian, P. Sáha, R. W. Rychwalski, J. Kubát, Polymer (2007)-accepted.

[12] M.E. Godard, J.M. Saiter, Physical aging in polymers: Comparison of two ways of determining Narayanaswamy’s parameter, Polym. Eng. Sci. 36 (1996) 2978-2985.

[13] J. Vernel, R.W. Rychwalski, V. Pelíšek, P. Sáha, M. Schmidt, F.H.J. Maurer, Physical aging in poly(ethylene oxide)/atactic-poly(methyl methacrylate) blends, Thermochim. Acta 342 (1999) 115-137.

[14] J.M. Hutchinson, D. McCarthy, S. Montserrat, P. Cotés, Enthalpy relaxation in a partially cured epoxy resin, J. Polym. Sci. Polym. Phys. 34 (1996) 229-239.

[15] C. Ramíres, M.J. Abad, J. Cano, J. López, P. Nogueira, L. Barral, Enthalpy relaxation in epoxycycloaliphatic amine resin, Colloid Polym Sci. 279 (2001) 184-189.

[16] J.M. Morancho, J.M Salla, Relaxation in a net epoxy and in the same resin modified with a carbonylterminated copolymer, J. Non-Cryst. Solids 235 (1998) 596-599.

[17] S. Montserrat, P. Cotés, Y. Calventus, J.M. Hutchinson, Effect of crosslink length on the enthalpy relaxation of fully cured epoxy-diamine resins, J. Polym. Sci. Polym. Phys. 38 (2000) 456-468.

[18] R. Wungtanagorn, S.J. Schmidt, Phenomenological study of enthalpy relaxation of amorphous glucose, fructose, and their mixture, Thermochim. Acta 369 (2001) 95-116.

[19] R. Svoboda, P. Pustková, J. Málek, Relaxation behavior of glassy selenium, J. Phys. Chem. Solids (2007), doi 10.1016/j.jpcs.2006.12.032.

[20] ASTM Standard D 864-52, Coefficient of cubical thermal expansion of plastics, (1952).

[21]A.J. Kovacs, Sur la variation isotherme du volume des hauts polymeres, Industrie de Plastiques 
Moderes 7 (1952) 30-34.

[22] J. Brandrup, E.H. Immegut, Polymer Handbook the 3rd edition, Wiley\& Sons Inc., New York, (1989), p. V/101.

[23]S. Fakirov, E.V. Fischer, G.F. Schmidt, Unit-cell dimensions of poly(ethylene terephthalate), Macromol. Chem. 176 (1975) 2459-2465.

[24] M. Delin, R.W. Rychwalski, J. Kubát, C. Klason, Physical aging time scales and rates for poly(vinyl acetate) stimulated mechanically in the $\mathrm{T}_{\mathrm{g}}$-region, Polym. Eng. Sci. 36 (1996) 2955-2967. 


\section{Figure captions}

Fig. 1. The schematic illustration of the three-step cycle method.

Fig. 2. The schematic illustration of volume, $V$, variation with temperature, $T$, (Part $\mathrm{A})$ and their derivative thermal expansion coefficient, $\alpha,($ Part B), during heating/cooling temperature scans [9].

Fig. 3. Dependences of specific volume on temperature during uniform cooling from equilibrium above $T_{g}$ and heating after annealing at $56^{\circ} \mathrm{C}$ for 440 hours at the $q_{1}=q_{2}=60^{\circ} \mathrm{C} \cdot \mathrm{h}^{-1}$.

Fig. 4. Dependence of specific volume on temperature as a function of the amount of isothermal relaxation, $\bar{\delta}_{V}$, at $60^{\circ} \mathrm{C}$, part $\mathrm{A}$, and $52^{\circ} \mathrm{C}$, part $\mathrm{B}$, prior to heating.

Fig. 5. Volume relaxation isotherms at $T_{a}=60^{\circ} \mathrm{C}$ and $52^{\circ} \mathrm{C}$ after cooling from equilibrium above $T_{g}$ at cooling rate $q_{1}=60^{\circ} \mathrm{C} \cdot \mathrm{h}^{-1}$.

Fig. 6. Dependence of inflection point temperature, $T_{i p}$, on the amount of volume relaxation at $60^{\circ} \mathrm{C}$ and $52^{\circ} \mathrm{C}$.

Fig. 7. Dependences of specific volume on temperature during heating after annealing at different $T_{a}$ for the same amount of volume isothermal relaxation, $\delta_{V}$. 
Tab. 1 Ranges of experimental variables defining three-step thermal cycles.

\begin{tabular}{|c|c|c|c|c|}
\hline \multicolumn{2}{|l|}{ Variable } & \multicolumn{3}{|c|}{ Values used } \\
\hline $\mathrm{T}_{0}\left[{ }^{\circ} \mathrm{C}\right]$ & 85 & 85 & 85 & 85 \\
\hline $\mathrm{t}_{0} \quad[\mathrm{~h}]$ & 0.25 & 0.25 & 0.25 & 0.25 \\
\hline $\mathrm{q}_{1}\left[{ }^{\circ} \mathrm{C} \cdot \mathrm{h}^{-1}\right]$ & 60 & 60 & 60 & 60 \\
\hline $\mathrm{T}_{\mathrm{a}}\left[{ }^{\circ} \mathrm{C}\right]$ & 60 & 56 & 52 & 48 \\
\hline $\mathrm{t}_{\mathrm{a}}[\mathrm{h}]$ & $4,43,140,270$ & 54,422 & $17,38,79,240,960$ & 144 \\
\hline $\mathrm{q}_{2} \quad\left[{ }^{\circ} \mathrm{C} \cdot \mathrm{h}^{-1}\right]$ & 60 & 60 & 60 & 60 \\
\hline
\end{tabular}


FIG. 1

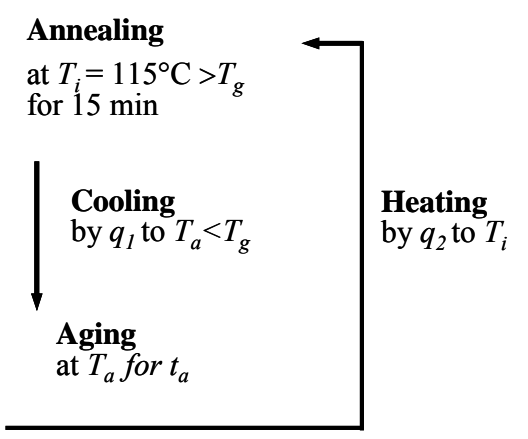

FIG. 2

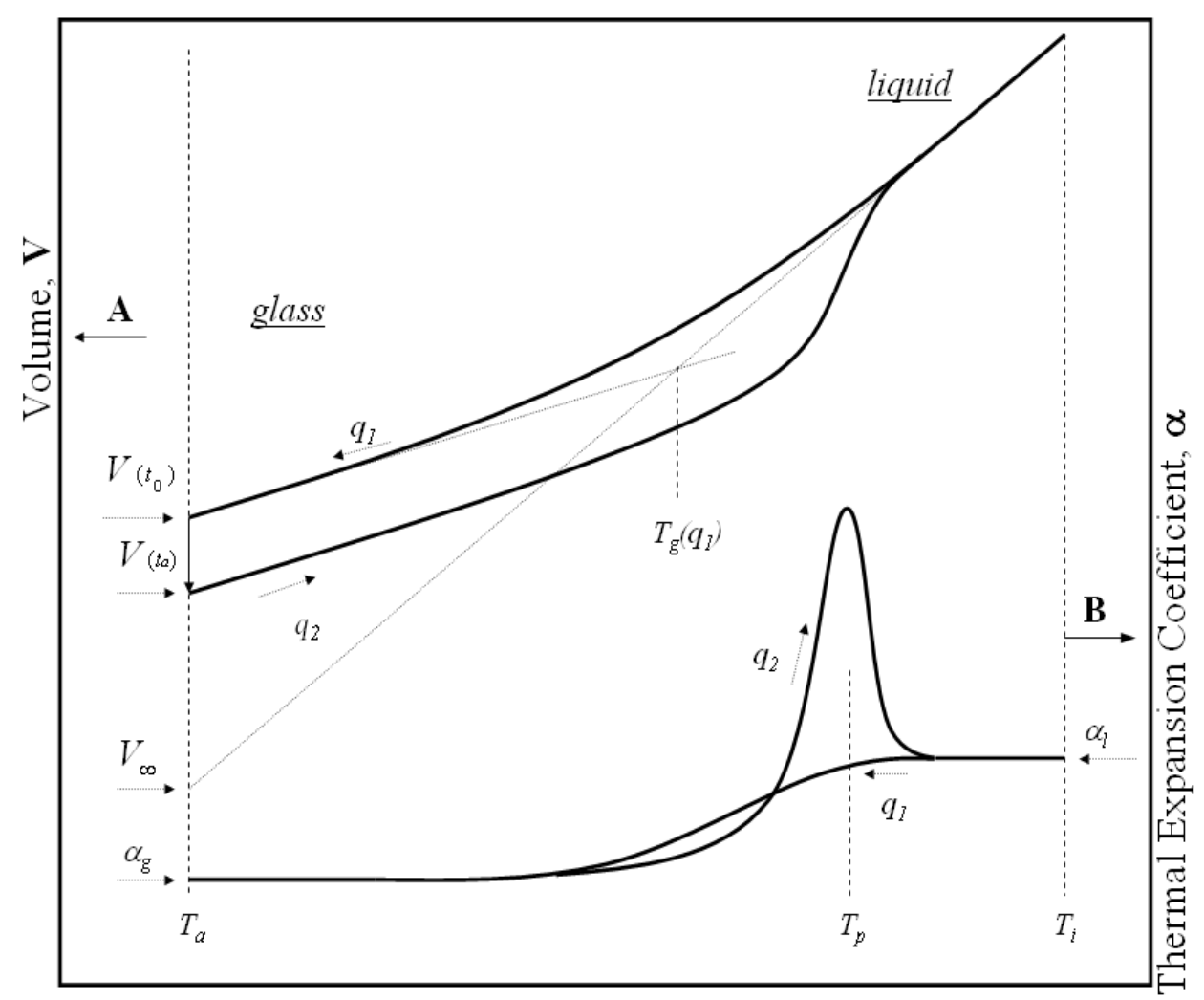

Temperature, $\mathbf{T}$ 
FIG. 3

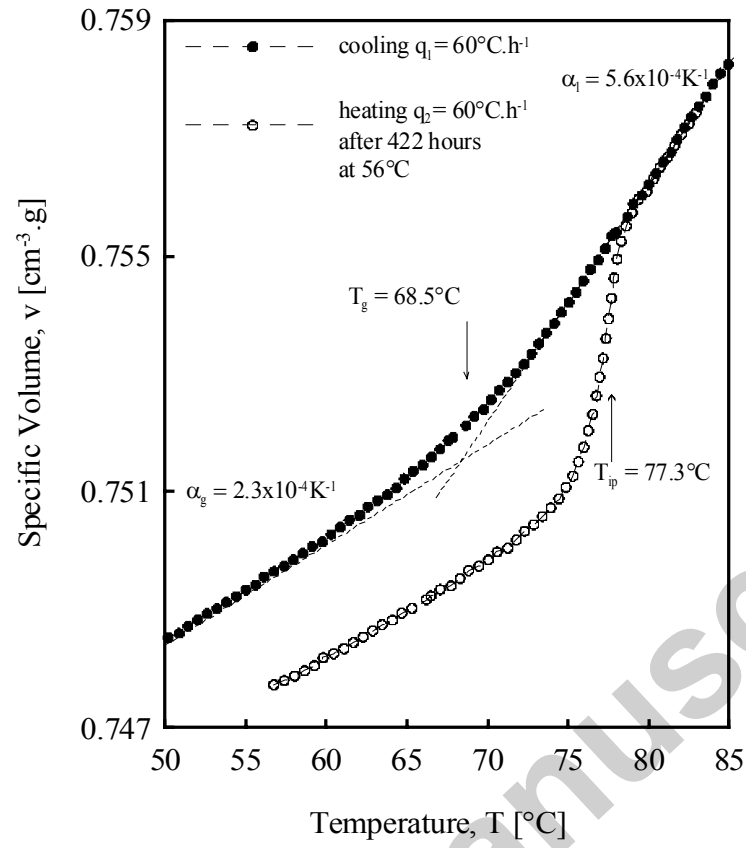

FIG. 4

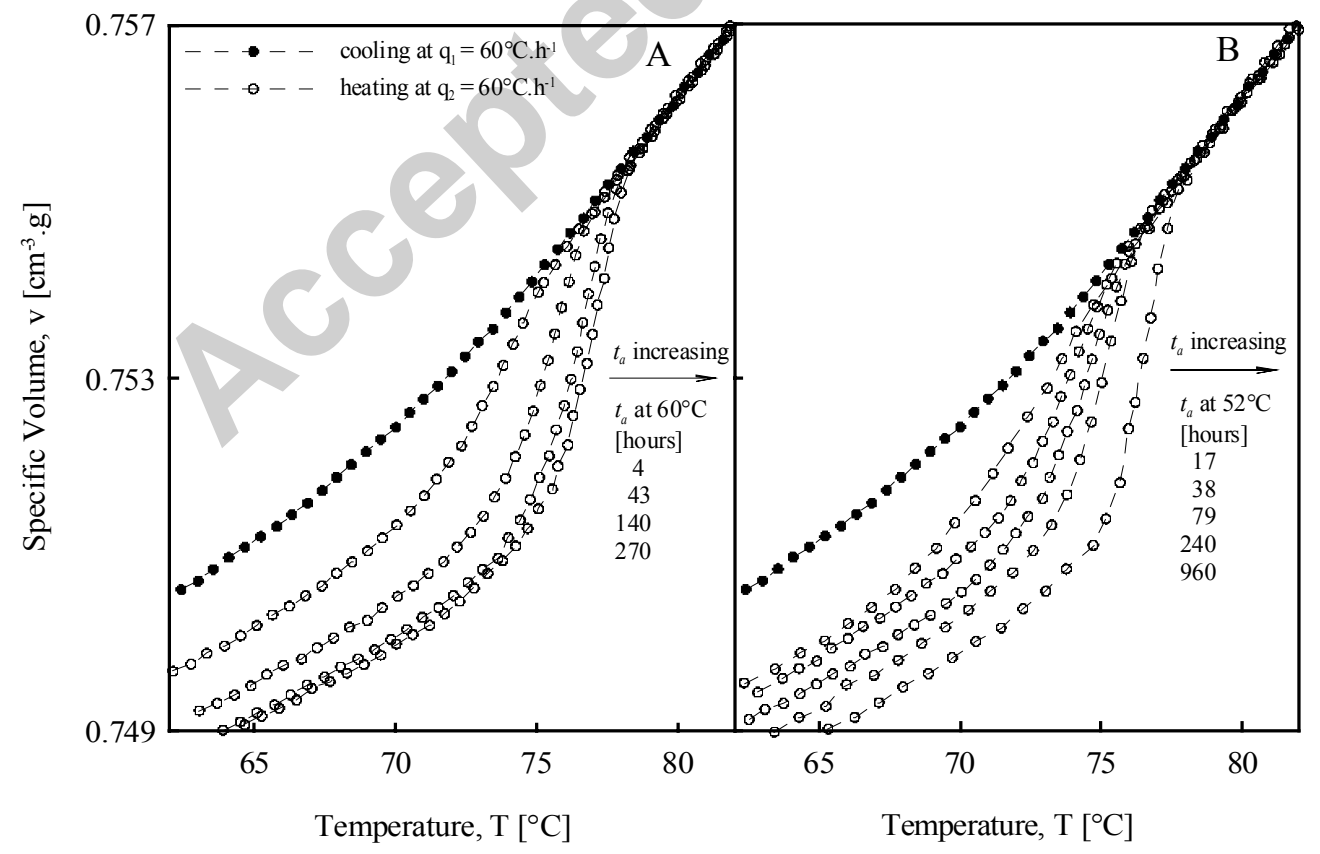


FIG. 5

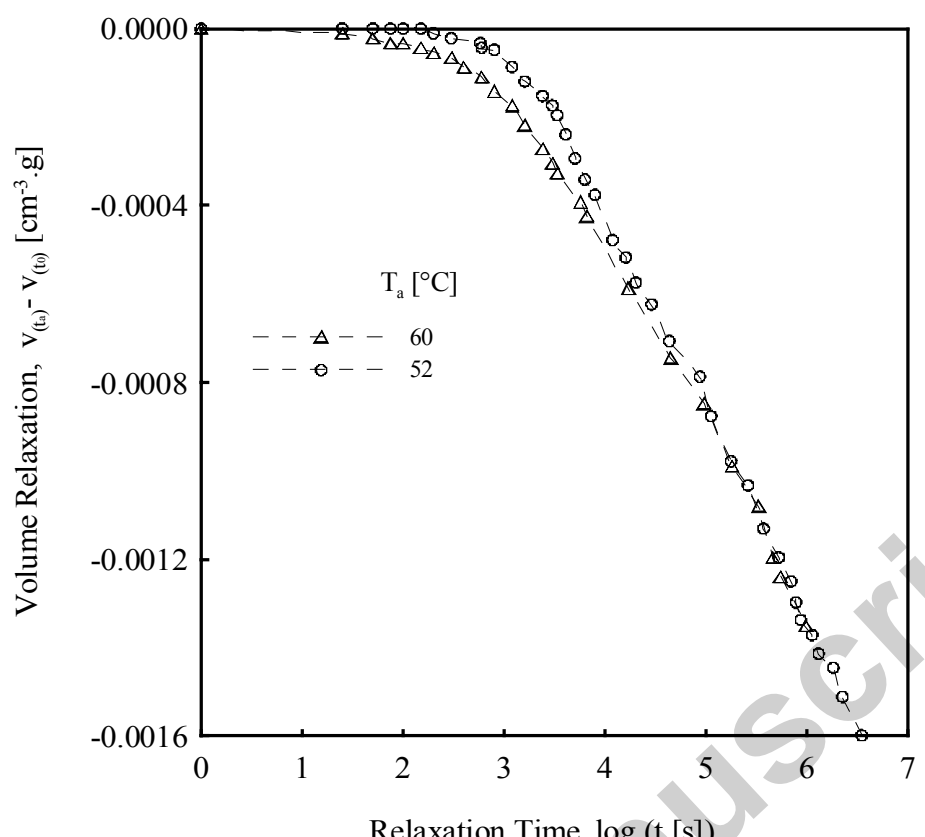

Relaxation Time, $\log \left(\mathrm{t}_{\mathrm{a}}[\mathrm{s}]\right)$

FIG. 6

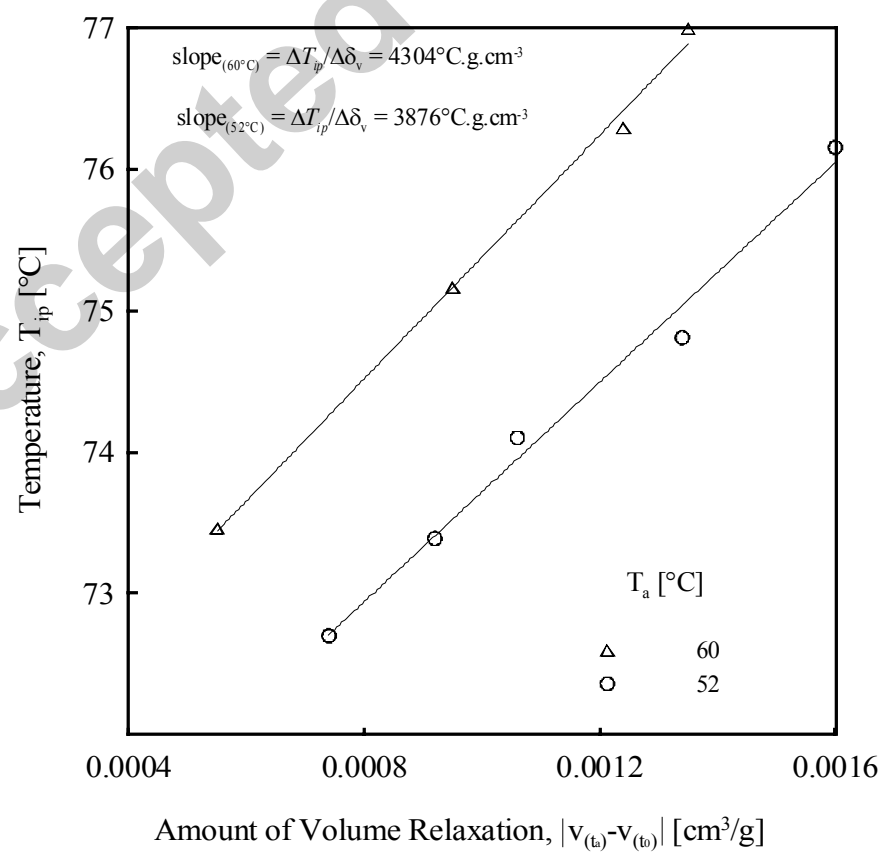


FIG. 7

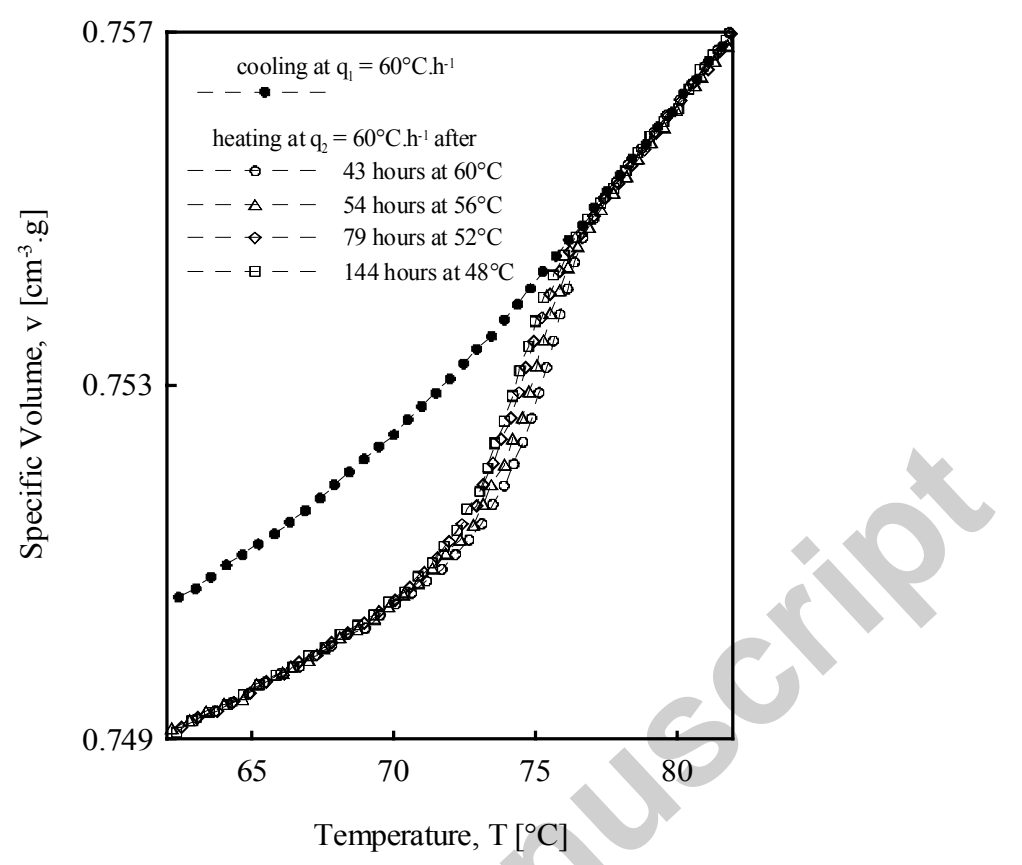

